Article

\title{
Dual Insecticidal Effects of Adenanthera pavonina Kunitz-Type Inhibitor on Plodia interpunctella is Mediated by Digestive Enzymes Inhibition and Chitin-Binding Properties
}

\author{
Caio Fernando Ramalho de Oliveira ${ }^{1}$, Taylla Michelle de Oliveira Flores ${ }^{2,3}{ }^{(1)}$, \\ Marlon Henrique Cardoso 2,4 $\left.{ }^{(}\right)$, Karen Garcia Nogueira Oshiro ${ }^{2,5}$, Raphael Russi ${ }^{6}$, \\ Anderson Felipe Jácome de França ${ }^{6}$, Elizeu Antunes dos Santos ${ }^{6}$ (D), Octávio Luiz Franco ${ }^{2,4,5}$, \\ Adeliana Silva de Oliveira ${ }^{6}$ and Ludovico Migliolo ${ }^{2,3,6, *(D)}$ \\ 1 Universidade Federal de Grande Dourados, Dourados, Mato Grosso do Sul, MS, 79825-070, Brazil; \\ oliveiracfr@gmail.com \\ 2 S-Inova Biotech, Programa de Pós-Graduação em Biotecnologia, Universidade Católica Dom Bosco, \\ Campo Grande, MS, 79117-900, Brazil; taylla.flores@outlook.com (T.M.d.O.F.); \\ marlonhenrique6@gmail.com (M.H.C.); oshiro.kgn@gmail.com (K.G.N.O.); ocfranco@gmail.com (O.L.F.) \\ 3 Programa de Pós-Graduação em Biologia Celular e Molecular, Universidade Federal da Paraíba, \\ João Pessoa, PB, 58059-900, Brazil \\ 4 Centro de Análises Bioquímica e Proteômicas, Programa de Pós Graduação em Ciências Genômicas e \\ Biotecnologia, Universidade Católica de Brasília, Brasília, DF, 70790-160, Brazil \\ 5 Programa de Pós-Graduação em Patologia Molecular, Faculdade de Medicina, Universidade de Brasília, \\ Brasília, DF, 70910-900, Brazil \\ 6 Programa de Pós-Graduação em Bioquímica, Universidade Federal do Rio Grande do Norte, \\ Natal, RN, 59078-900, Brazil; raphaelrussi@gmail.com (R.R.); andersonfjf@gmail.com (A.F.J.d.F.); \\ elizeu.ufrn@gmail.com (E.A.d.S.); cisteana@yahoo.com.br (A.S.d.O.) \\ * Correspondence: ludovico@ucdb.br
}

Academic Editor: Massimiliano Fenice

Received: 19 September 2019; Accepted: 14 October 2019; Published: 28 November 2019

\begin{abstract}
The Indianmeal moth, Plodia interpunctella, is one of the most damaging pests of stored products. We investigated the insecticidal properties of ApKTI, a Kunitz trypsin inhibitor from Adenanthera pavonina seeds, against $P$. interpunctella larvae through bioassays with artificial diet. ApKTI-fed larvae showed reduction of up to $88 \%$ on larval weight and $75 \%$ in survival. Trypsin enzymes extracted from P. interpunctella larvae were inhibited by ApKTI, which also demonstrated capacity to bind to chitin. Kinetic studies revealed a non-competitive inhibition mechanism of ApKTI for trypsin, which were further corroborated by molecular docking studies. Furthermore, we have demonstrated that ApKTI exhibits a hydrophobic pocket near the reactive site loop probably involved in chitin interactions. Taken together, these data suggested that the insecticidal activity of ApKTI for P. interpunctella larvae involves a dual and promiscuous mechanisms biding to two completely different targets. Both processes might impair the P. interpunctella larval digestive process, leading to larvae death before reaching the pupal stage. Further studies are encouraged using ApKTI as a biotechnological tool to control insect pests in field conditions.
\end{abstract}

Keywords: non-competitive inhibitor; trypsin inhibitor; peritrophic membrane

Highlights

- $\quad$ ApKTI increases mortality of P. interpunctella larvae. 
- In vitro analyses showed that ApKTI presents chitin-binding properties.

- In silico structural studies corroborated protein-protein and protein-carbohydrate interactions.

\section{Introduction}

Insect pests are responsible for immense losses in the field and storage conditions. Annually, billions of dollars are spent in crop protection, mainly with highly toxic insecticides [1]. As consequence of the massive use of chemical insecticides, the reduction of natural biodiversity near crops and the selection of resistant insect pest have been reported [2]. The overwhelming resistance of insects against chemical pesticides encourages the investments on alternative control strategies, including pyramiding of genes with insecticidal activity [1,3,4]. Plodia interpunctella (Hübner) (Lepidoptera: Pyralidae) is a widely distributed insect pest from temperate and tropical areas [3]. During its larval stage, P. interpunctella prompts significant economic impacts on stored foods, such as cereals, legumes, dried fruits, and nuts [5].

Studies regarding the digestion process in insects, the gut morphology, compartmentalization, and function have emerged features which might be applied in pest control strategies [6,7]. Therefore, the use of molecules to impair the functional digestive physiology might impact insects' development with direct consequences on both weight and survival. For instance, most Lepidopteran present serine-peptidases, especially trypsin and chymotrypsin, as major enzymes for initial digestion of dietary proteins. Thus, the use of molecules capable of interfering with proteolysis raises diverse impacts on larval development.

Diverse plant proteins display insecticide activity. The plant defense mechanisms against insects are result of a co-evolution of hundreds of millions of years [8]. Among the proteinaceous compounds, plant peptidase inhibitors (PIs) appear as a promising group for heterologous expression in crops. PIs can also be found in different plant tissues, contributing to plant defense against herbivory through the inhibition of insect gut peptidases, reducing the availability of amino acids necessary for growth and development [9]. Genes encoding plant PIs for the transformation of crops have been reported as an alternative to control insect pests [10-12].

Some PIs bind to chitin $[5,13]$, a polysaccharide present in multiple structures and also at insects' peritrophic membrane (PM). The PM is an anatomical structure that surrounds the food bolus in the insect gut, displaying a dual function: (i) Compartmentalization of the digestive process; and (ii) facilitation of the food bolus movement [7]. The binding or interference in PM homeostasis impairs nutrient absorption, decreasing the larval weight and increasing the mortality $[5,13]$. Therefore, the PM has been considered an important target for insecticidal agents' development, and the consumption of PIs by insect larvae can be used to affect the PM homeostasis.

The Kunitz trypsin inhibitor, ApKTI, has been isolated from Adenanthera pavonina Linnaeus seeds (Fabaceae: Mimosoideae) [14]. ApKTI consists of a double polypeptide chain and is capable of inhibiting two different classes of peptidases, including serine- and cysteine-peptidases [15]. Thus, studies have shown that ApKTI is effective in controlling insect pests from different orders, including Lepidoptera [16,17], Coleoptera [9], and Diptera [18]. Based on that, here we aimed to investigate the effects of ApKTI on P. interpunctella larval development. The insecticide properties of ApKTI were investigated in vivo, followed by in vitro assays and bioinformatics studies to determine ApKTI's possible targets in P. interpunctella larval gut. Finally, we used molecular docking to investigate the binding mode of ApKTI on trypsin, chymotrypsin, and N-acetylglucosamine (GlcNAc-the elementary unit of chitin), explaining how ApKTI binds to chitin and inhibits digestive enzymes, influencing negatively the $P$. interpunctella development. 


\section{Results}

\subsection{Bioassays with P. Interpunctella Larvae}

We carried out bioassays to investigate the potential of ApKTI as insecticide agent. Artificial diets were prepared with different ApKTI concentrations $(0.3 \%-1.5 \% w / w)$ and offered to P. interpunctella neonate larvae. Following a chronic exposure to ApKTI over 15 days, the larval weight, survival and enzymatic activity were analyzed. ApKTI-fed larvae presented a clear dose-dependent reduction on both weight and survival. The highest concentration of ApKTI into artificial diet resulted in a reduction of $88 \%$ and $75 \%$ on larval weight and survival, respectively (Figure $1 \mathrm{~A}, \mathrm{~B}$ ). Through bioassays we demonstrated that ApKTI showed insecticide activity against P. interpunctella larvae (Figure 1C).

A

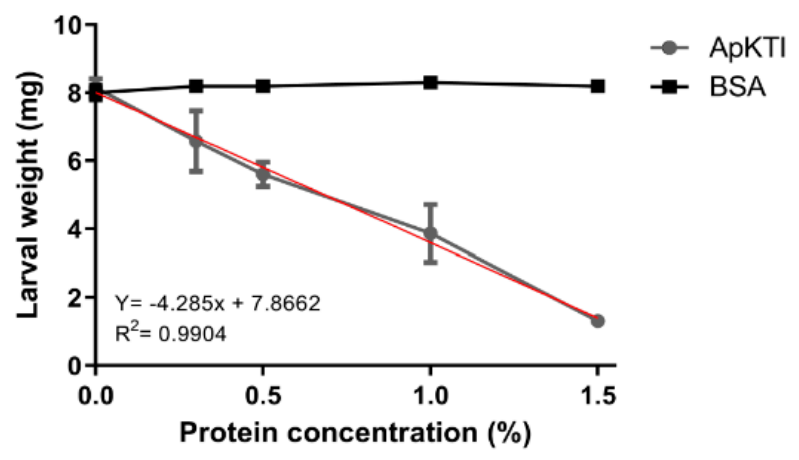

B

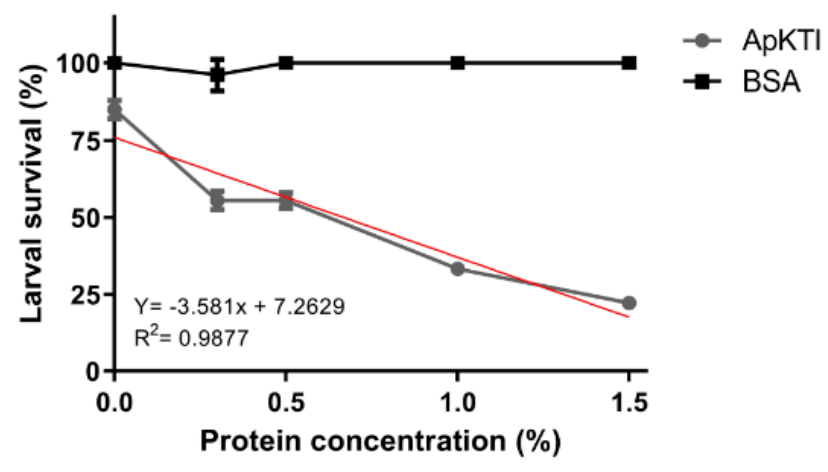

C

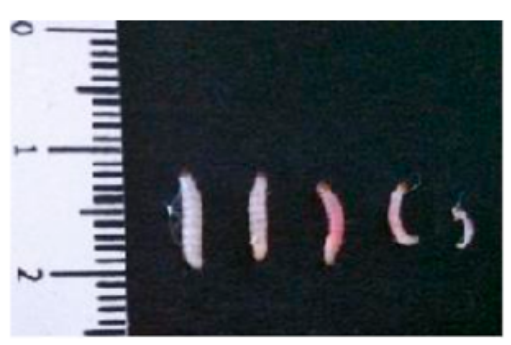

Figure 1. Bioassays with P. interpunctella larvae. Artificial diet was enriched with ApKTI from $0.3 \%$ to $1.5 \%(w / w)$. At the final of bioassays (15 days) the weight (A) and survival (B) in each treatment were determined. In control treatment the artificial diet was supplemented with bovine serum albumin (BSA) at the same concentration of ApKTI. A linear regression was obtained from ApKTI-fed larvae demonstrating the dose-response effect. (C) Representative image of larvae of each treatment, in sequential order from the left: control-fed larvae, larvae fed with $0.3 \%, 0.5 \%, 1.0 \%$, and $1.5 \%$ ApKTI. 


\subsection{Purification of Trypsin Inhibitor from Adenanthera Pavonina Seeds (ApKTI)}

Initially, a precipitation with ammonium sulfate was used to fractionate the crude extract into fractions. Afterwards, the inhibitory activity against trypsin was determined to each fraction. We observed that the fraction $40 \%-60 \%$ from ammonium sulfate precipitation showed the highest inhibitory activity against trypsin. This fraction was chosen to further purification of ApKTI. First, the fraction $40 \%-60 \%$ was applied into gel filtration chromatography, resulting in two peaks: (i) A first peak corresponding to high molecular mass proteins and; (ii) a second peak containing a mix of intermediate and low molecular mass proteins. The fractions collected at the final portion of the second peak revealed trypsin inhibitory activity (Figure 2A). These active fractions were pooled and applied onto an affinity trypsin-Sepharose column (Figure 2B). The chromatogram of trypsin-Sepharose column showed proteins eliminated during the washing step with no affinity by column. The elution of fractions adsorbed to column, started from fraction 20, resulted in elution of a single peak. This peak showed inhibitory activity against trypsin and, therefore, was named ApKTI (Figure 2B).

\section{A}

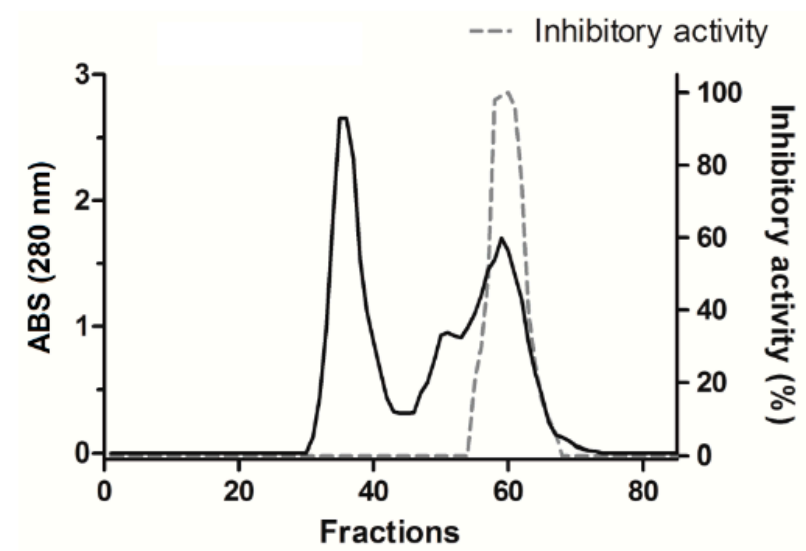

B

--. Inhibitory activity

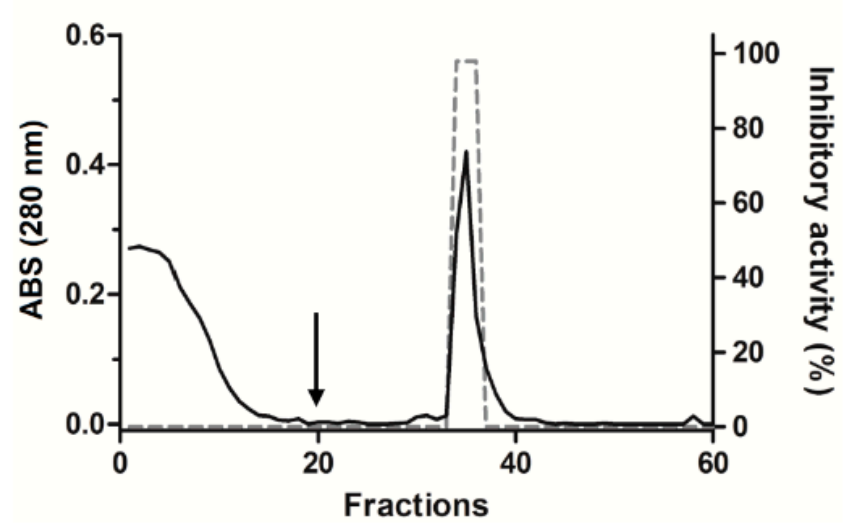

Figure 2. Purification of ApKTI. (A) The fraction F40-60\% from ammonium sulfate precipitation was fractioned in Sephacryl S-100 column. (B) The active fractions were purified in trypsin-Sepharose column. The arrows indicate the beginning of elution with $\mathrm{HCl} 100 \mathrm{mM}$ in trypsin-Sepharose and chitin columns. All fractions had the inhibitory activity against trypsin assayed. The inhibitory activities are showed as dotted lines.

A chromatography using chitin as matrix was used to investigate whether ApKTI possesses chitin-binding properties. Chitin was used since this polysaccharide is a major constituent of PM, 
being a possible target of ApKTI into larval gut. ApKTI was injected into the chitin column and no peaks were detected during the column-washing step. Following the elution step using $\mathrm{HCl}$, a single peak was noticed (Figure 3). Further assays confirmed that the eluted peak showed inhibitory activity against trypsin (data not shown). Based in this result, we demonstrated that ApKTI possesses chitin-binding properties.

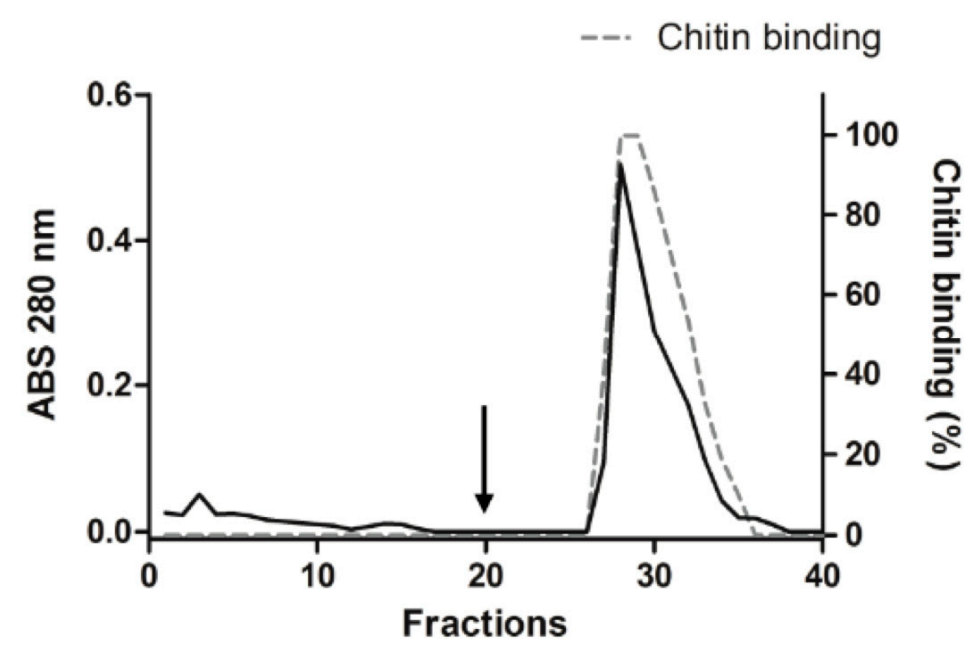

Figure 3. Binding of ApKTI in chitin column chromatography was used to demonstrate the affinity. The dotted line represents the binding of ApKTI in chitin column.

\subsection{In Vitro Enzymatic Assays}

Following the studies regard chitin-binding properties, enzymatic assays using P. interpunctella gut extract as source of enzymes were carried out to investigate the effects of ApKTI on inhibition of digestive enzymes, another possible target into larval gut. For detection of inhibitory activity against trypsin we used the specific substrate BApNA. The gradual increasing of ApKTI concentration led to reduction of trypsin activity of $P$. interpunctella gut extract. The maximal inhibitory activity (90.6\%) was obtained in the presence of $15 \mu \mathrm{g}$ ApKTI. Moreover, a kinetic study carried out with different concentrations of ApKTI and BApNA revealed a non-competitive inhibition mechanism of ApKTI for P. interpunctella trypsin (Figure 4). Dixon Plot revealed that lines corresponding to the concentrations of the substrates converge to a common point in the $X$-axis. The $K i$ value was obtained $(504.7 \mathrm{nM})$ after determination of $\mathrm{Km}$ and $V_{\text {max }}$, in agreement with the $K i$ of other non-competitive PIs [19]. These results indicate a clear trypsin inhibitory activity based in a non-competitive mechanism. To gain insights this result a molecular level, were further investigated the binding of ApKTI with chitin and serine-peptidases through in silico experiments.

\subsection{Structural Studies}

After modeling, validation procedures and tridimensional fold checking, we investigated the molecular mechanism of ApKTI binding to GlcNAc, a monosaccharide that constitutes the chitin polymer. The affinity value obtained for ApKTI/[(GlcNAc) $)_{3}$ was $-8.9 \mathrm{kcal}^{\mathrm{mol}}{ }^{-1}$. As summarized in Table S1, all predicted atomic interactions were characterized as hydrogen bonds (HB), with a small number of interactions with larger distances were predicted (6 HBs).

For complex with GlcNAc, Arg $^{64}$ as well P2 residue from the reactive site loop of ApKTI, Arg ${ }^{66}$, were involved in stabilization, beyond the amino acid residues Glu ${ }^{77}$, $\mathrm{Thr}^{75}$, and Gln ${ }^{112}$ (Figure 5; Table S1). These residues are near a hydrophobic patch, where part of the GlcNAc structure anchored. Regarding the ApKTI binding ability to GlcNAc, the involvement of the reactive site loop region flanked by a hydrophobic patch connecting antiparallel $\beta$-strand arrangement in ApKTI is involved 
in the insertion of GlcNAc. Therefore, through in silico results we suggested the mechanism and molecular region of ApKTI involved with binding to chitin.

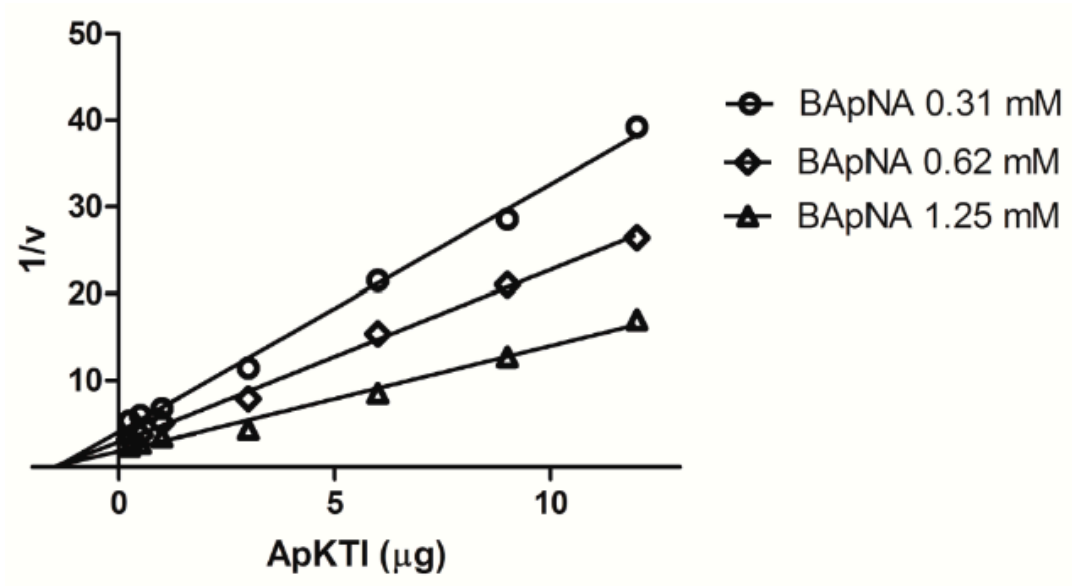

Figure 4. Binding mode between ApKTI and trypsin. Kinetic studies were carried out using different concentration of inhibitor and substrate. Following the Michaelis-Menten parameters determination, the Dixon plot was obtained. The points where lines intersect the $X$-axis converge to a common point, while different $1 / \mathrm{V}$ were observed, determining a non-competitive inhibition mechanism between ApKTI and trypsin.
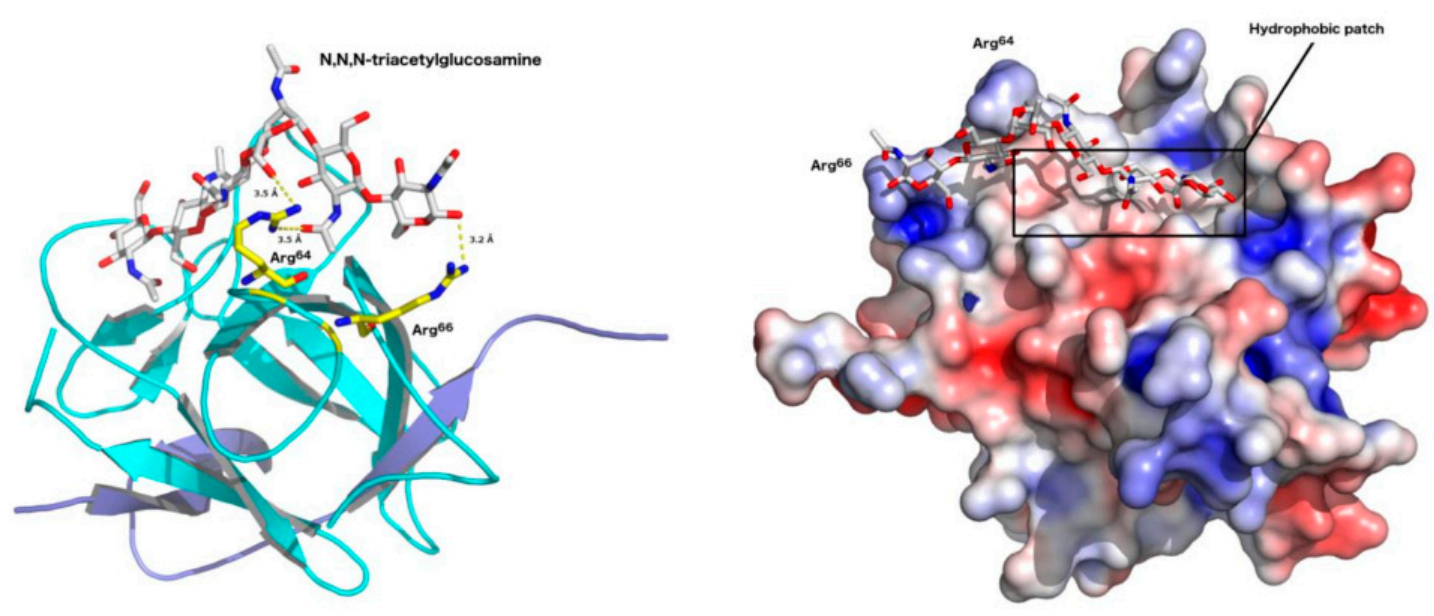

Figure 5. Tri-N-acetylglucosamine in complex with ApKTI, where $\mathrm{Arg}^{64}$ and $\mathrm{Arg}^{66}$ located at the reactive site loop from ApKTI are involved in the complex stabilization (left). Adaptive Poisson-Boltzmann solver (APBS) electrostatic potential of ApKTI (potential ranges from $-5 \mathrm{kT} / \mathrm{e}$ (red) to $+5 \mathrm{kT} / \mathrm{e}$ (blue)), highlighting the $\mathrm{Arg}^{64}$ and $\mathrm{Arg}^{66}$ residues and the hydrophobic pocket involved in GlcNAc attachment (right).

\subsection{Structural Studies}

We carried out further molecular modeling and docking simulations to obtain insights on the binding mode of the molecular complexes ApKTI/trypsin and ApKTI/chymotrypsin. Molecular modeling simulations were carried out to predict the atomic coordinates of ApKTI, trypsin and chymotrypsin, thus generating reliable tridimensional structures for docking studies. The lowest free-energy models were selected and validated as described in the methodology. All models generated by comparative modeling presented $>80 \%$ amino acid residues in the most favorable regions in the Ramachandran Plot. Moreover, the calculated overall G-factors (average scores for the dihedral angles and the main-chain covalent forces) ranged from -0.23 to -0.26 for all models here studied, indicating reliable structures regarding stereochemical parameters (reference value: $>0.5$ ). The fold quality 
of each model was also confirmed, with calculated z-scores of $-4.8,-6.52$, and -6.47 for ApKTI, trypsin and chymotrypsin, respectively (Table 1). Structurally, ApKTI theoretical model adopted a loop connecting $\beta$-strand scaffold with two polypeptide chains stabilized by two disulfide bonds. The ApKTI reactive site loop is composed by Thr, Pro, Arg, Ile, Tyr, and Gly amino acid residues (Figure 6A,C). The theoretical models for trypsin and chymotrypsin from P. interpunctella showed two main cores formed by antiparallel $\beta$-strands, as well as $\alpha$-helix and loop arrangements (Figure 6A,C).

A

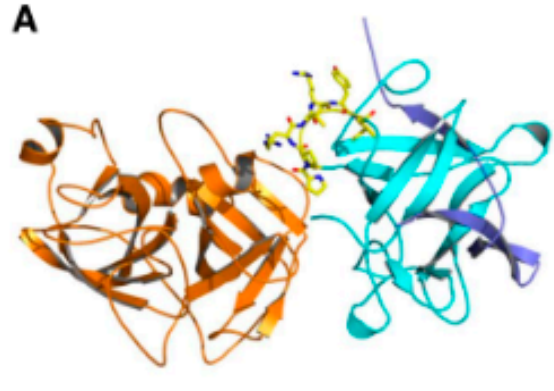

C

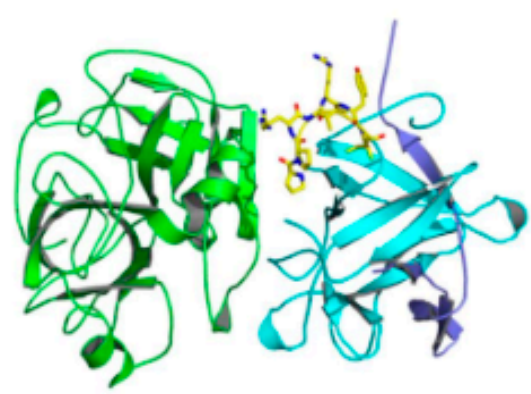

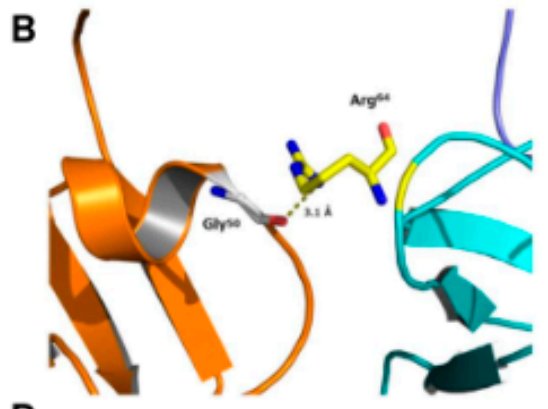

D

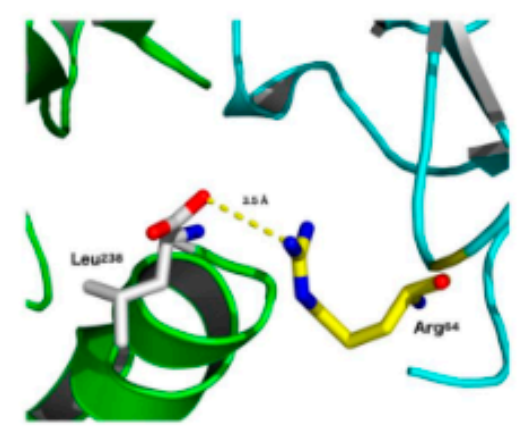

Figure 6. Tridimensional theoretical models for ApKTI, trypsin and chymotrypsin from P. interpunctella. $\beta$-strand scaffold showed two main cores formed by antiparallel $\beta$-strands, as well as $\alpha$-helix and loop arrangements are observed in both enzymes. Predicted conformations for the (A) ApTI/trypsin and (C) ApTI/chymotrypsin complexes (yellow sticks represent the reactive site loop of ApTI). Atomic interactions involving $\mathrm{Arg}^{64}$ located at the reactive site loop from ApKTI are highlighted in the (B) ApKTI/trypsin and (D) ApTI/chymotrypsin complexes. Trypsin and chymotrypsin active sites are highlighted as white sticks.

After modeling, validation procedures and tridimensional fold checking, ApKTI, trypsin, and chymotrypsin were submitted to molecular docking studies. In this context, two molecular complexes were here analyzed. The best affinity values obtained for ApKTI/trypsin, and ApKTI/chymotrypsin were -13.3 and $-13.4 \mathrm{kcal}^{\mathrm{mol}}{ }^{-1}$, respectively. As summarized in Table S1, all predicted atomic interactions were characterized as hydrogen bonds (HB), with distances between 2.7 to $3.6 \AA$. A total of $7 \mathrm{HB}$ were predicted for ApKTI/trypsin; whereas $10 \mathrm{HB}$ could be calculated for the ApKTI/chymotrypsin complex. However, even though ApKTI/chymotrypsin presents a higher number of interactions, as well as a slightly better affinity, the distances of interactions for the complex ApKTI/trypsin appear to be shorter, which might explain its similar binding affinity with ApKTI/chymotrypsin. In complexes with enzymes, crucial amino acid residues such as $\mathrm{Arg}^{64}$, located at position P1 from the reactive site loop of ApKTI, and $\mathrm{Arg}^{138}$, were always involved in the stabilization of the complexes (Figure 6B,D; Table S1). 
Table 1. Structural statistics for the tridimensional theoretical models generated in this study for ApKTI, trypsin and chymotrypsin.

\begin{tabular}{|c|c|c|c|c|c|c|c|c|}
\hline \multirow[b]{2}{*}{$\begin{array}{l}\text { Predicted } \\
\text { Structures }\end{array}$} & \multirow{2}{*}{$\begin{array}{l}\text { Sequence } \\
\text { Length }\end{array}$} & \multirow{2}{*}{$\begin{array}{l}\text { Fold Quality } \\
\text { (z-Score) }\end{array}$} & \multirow{2}{*}{$\begin{array}{l}\text { Stereochemistry } \\
\text { (G-Factors) }\end{array}$} & \multicolumn{3}{|c|}{ Ramachandran } & \multirow{2}{*}{$\begin{array}{l}\text { Bad Bonds } \\
\quad(\%)\end{array}$} & \multirow{2}{*}{$\begin{array}{c}\text { Bad Angles } \\
(\%)\end{array}$} \\
\hline & & & & $\begin{array}{c}\text { Most Favored } \\
(\%)\end{array}$ & $\begin{array}{c}\text { Allowed } \\
(\%)\end{array}$ & $\begin{array}{c}\text { Outliers } \\
(\%)\end{array}$ & & \\
\hline ApKTI & 176 & -4.80 & -0.26 & 89.00 & 95.9 & 4.07 & 0 & 1.09 \\
\hline Trypsin & 233 & -6.52 & -0.23 & 90.48 & 96.1 & 3.90 & 0 & 1.87 \\
\hline Chymotrypsin & 238 & -6.47 & -0.24 & 91.50 & 97.9 & 2.12 & 0 & 1.70 \\
\hline
\end{tabular}

The z-scores obtained for all structures here reported are in agreement with those with similar size, structurally determined by X-ray crystallography and deposited in the Protein Data Bank (PDB). The G-factors indicate that the overall average for the dihedral angles, along with the main-chain covalent forces for each structure are within the expected values for reliable structures (G-factors > -0.5). The structural validations were performed on ProSa-web [20], PROCHECK [21] and MolProbity [22]. 
Furthermore, we also described a non-competitive inhibition mechanism between ApKTI and serine-peptidases, corroborating in vitro assays, once that no interactions were predicted between ApKTI reactive site loop and the active site of trypsin and chymotrypsin. The binding between ApKTI and enzymes makes it difficult for substrates to occupy the enzymatic active site, reducing enzymatic catalysis in the presence of the inhibitor. Taken together, in silico results supported the non-competitive inhibition mode of ApKTI for trypsin and chymotrypsin.

\section{Discussion}

Currently, most efforts for crop protection reside in both $B t$ technology and massive use of insecticides. However, the events of insect resistance against insecticides and $B t$ crops are overwhelming reported $[2,23,24]$. The consequence of systematic insecticide application resides on insect resistance and lethal effects on non-target organisms, including parasites, parasitoids, and pollinators. Moreover, insecticides also represent a huge threat to the environment and human health. For this reason, alternative tools to reduce losses in field have been investigated. The expression of plant defense proteins in crops has been studied since the late 1980s [11,12,25,26]. Plant defense proteins, including ApKTI, are result of insect-plant coevolution of millions of years [27]. Naturally, PIs are expressed in diverse plant tissues, including tubers, leaves, flowers, and seeds [28]. Several crops consumed by humans are rich in PIs, such as soybean, beans, tomato, potato, and legume seeds in general [29], reaffirming that the introduction of PIs coding genes in plants is more likely not to compromise human health. However, prior the development of transgenic plants expressing PIs, extensive studies have to be carried out to evaluate the effects of a PI on target insects, as insect pests are known to overcome the insecticide effects of PIs by modulating digestive enzymes expression [30-33].

The purification of ApKTI was firstly reported in 1986 by Richardson and collaborators [14]. Since then, the insecticidal activity of ApKTI has been investigated against Coleoptera [9] and Lepidoptera [16,17]. The ability of ApKTI to inhibit enzymes from different classes has been previously studied [15]. However, to the best of our knowledge is the first time that the binding of ApKTI to chitin has been suggested. Although it seems new, the description of multi-activity plant proteins is already described in the literature. Several examples include storage proteins with chitin-binding properties [34], plant inhibitors with antimicrobial [35] and antiparasitic activities [36]. These finding demonstrated that plant proteins, including PIs, might assume a similar fold with a diversity of biological functions. Talisia esculenta (Sapindaceae) seeds contain an insecticide storage protein named Talisin, that shows both lectin-like properties and inhibitory activities [37]. A Kunitz inhibitor purified from Entada acaciifolia seeds, named EATI, presented inhibitory activity against trypsin [38]. Despite its high inhibitory affinity for trypsin, we recently observed through immunofluorescence assays that EATI also binds to peritrophic membrane of a lepidopteran larvae, Spodoptera frugiperda (data not published). The literature point that the defensive functions of PIs are not restricted to insect enzyme inhibition [39].

The importance of ApKTI binding to chitin is related to PM composition, given the significance of PM in protection against mechanical damage, microorganisms and parasites invasion [7]. The PM integrity is directly involved in high digestive efficiency observed among insects, as it creates compartments for initial, intermediate and final digestion and serves as site to anchorage digestive enzymes [7]. Our results show that ApKTI acts through enzymatic inhibition and chitin binding, being able to trigger PM perturbations.

Is important to note that in our bioassays with P. interpunctella larvae, the concentrations of ApKTI were similar to reports carried out with PIs incorporated in artificial diets [38,40] or even transgenic plants expressing PIs [11,12]. In a similar study, Amorim and collaborators [5] demonstrated that SBTI, a competitive trypsin and chymotrypsin inhibitor from soybean, was ineffective against $P$. interpunctella. SBTI-fed larvae presented neither mortality nor weight reduction when an artificial diet was supplemented up to $4 \%$ of SBTI. The differences between ApKTI and SBBI effects on P. interpunctella might be related to their different enzymatic inhibition mechanisms. SBBI is a competitive inhibitor, 
therefore, its reactive site forms a tight complex with the enzyme active site, which composed by Asn, His and Ser residues. ApKTI is a non-competitive inhibitor, thus, its reactive site binds to residues located out of the enzyme active site. For trypsin, ApKTI binds to Gly ${ }^{50}$ and neighbor amino acids; for chymotrypsin, ApKTI binds to a region near Leu ${ }^{238}$ (Table S1). The adaptation of Lepidopteran to serine-peptidases is a phenomenon well described [31,32,41]. In general, a differential transcription of enzymes with a reduced affinity for plant PIs allows the insects to perform protein digestion without interference of ingested PIs. The resistant enzymes present amino acid substitutions of conserved residues involved in interactions between the enzyme active site and PIs reactive loop [42,43]. It results in a reduced affinity between resistant enzymes and competitive PIs. The evolution selected subsites in insects' trypsin progressively more hydrophobic, whereas plant PIs present polar residues at their reactive site $[44,45]$. Considering that ApKTI is a non-competitive inhibitor, the affinity for trypsin is not expected to be affected by amino acid substitution at the enzyme active site. This feature represents benefits over competitive inhibitors.

The modeling of ApKTI showed twelve antiparallel $\beta$-sheets along two polypeptide chains, a structural fold previously reported [15] and well described for other Kunitz-type inhibitors [42]. The theoretical models for trypsin and chymotrypsin from P. interpunctella are also in agreement with serine-peptidases characterized previously [18]. These findings have been described in previous reports carried out with Kunitz-type inhibitors [18,46-48], supporting the accuracy of our in silico data. Moreover, the distances of hydrogen bonds between ApKTI/trypsin (2.7-3.6 $\AA$ ) and ApKTI/chymotrypsin (3.0-3.6 $\AA$ ) are in agreement with data from the literature for docking studies with serine peptidases and PIs [15,49]. Moreover, we demonstrated that hydrogen bonds play a crucial role in ApKTI stabilization with trypsin, chymotrypsin and GlcNAc.

Our bioassays showed that ApKTI displays insecticide activity on P. interpunctella larvae. Moreover, we propose that ApKTI might affects the P. interpunctella larvae development by two distinct mechanisms: (i) Inhibition of digestive enzymes and (ii) binding to chitin present in PM. The inhibition of a fraction of digestive enzymes impair the digestive process, with direct effects on larval performance. The binding of ApKTI to chitin might impairs the functioning of PM, such as obstructing the endo-ectoperitrophic circulation of food and enzymes, reducing the digestive efficiency [47] or the enzyme recycling. However, a conclusive finding would be obtained through ultrastructural study targeting the PM integrity.

\section{Material and Methods}

\subsection{Chemicals}

N-benzoyl-D-L-arginine-p-nitroanilide (BApNA), bovine serum albumin (BSA), bovine pancreatic trypsin, Trypsin-chymotrypsin inhibitor from Glycine max (SBBI) and Chitin from shrimp shells were purchased from Sigma Chemical Co. (St. Louis, MO, USA). All other chemicals and reagents used were of analytical grade.

\subsection{Insects}

Larvae of $P$. interpunctella were maintained in the Department of Genetics and Cell Biology, Bioscience Center, Federal University of Rio Grande do Norte, Natal, Brazil, and fed with artificial diet (10.4\% finely ground sugar cane fibers, 3\% wheat germ, $6.5 \%$ wheat flour, $12 \%$ crystal sugar, $9.9 \%$ yeast, $0.3 \%$ sodium benzoate, $0.9 \% \mathrm{HCl}$ and $57 \% \mathrm{H}_{2} \mathrm{O}$ ), at $25-30{ }^{\circ} \mathrm{C}$ and relative humidity of $70 \%-80 \%$ [5].

\subsection{Bioassays with Plodia Interpunctella Larvae}

The effect of ApKTI on P. interpunctella larval development was investigated in bioassays using artificial diet, based on a mixture of wheat flour (2.3 g), brewer's yeast (2.5 g), white sugar (3.0 g), and sodium benzoate $(0.07 \mathrm{~g})$ for a total of $8 \mathrm{~g}$ of the mixture. The ingredients were homogenized for obtainment of fine flour. Artificial diets with different ApKTI concentrations were prepared, 0.3\%; 
$0.5 \% ; 1.0 \%$; and $1.5 \%(w / w)$. The control group had the artificial diet enriched with BSA at the same concentrations used for ApKTI. The artificial diets $(800 \mathrm{mg})$ were placed individually in in 6-well microplates and each well received nine neonatal larvae and the plates wrapped with clear PVC film were maintained at temperature of $25 \pm 1.0^{\circ} \mathrm{C}$, relative humidity of $60 \%-70 \%$ during 15 days. After this period, the larvae were weighed for determination of average larval weight and survival. The bioassay was carried out in triplicate.

\subsection{Purification of Trypsin Inhibitor from Adenanthera Pavonina Seeds (ApKTI)}

A. pavonina seeds were obtained locally (Campo Grande-MS) and stored at $-20{ }^{\circ} \mathrm{C}$ until use. The A. pavonina fine-grained flour from seeds was obtained and subjected to extraction with sodium tetraborate $50 \mathrm{mM}$ buffer, $\mathrm{pH}$ 7.5, in the ratio 1:10 (flour: buffer), during $3 \mathrm{~h}$ under stirring at room temperature. After, it was centrifuged at $12,000 \times \mathrm{g}$, for $30 \mathrm{~min}$, at $4{ }^{\circ} \mathrm{C}$. The supernatant was submitted to a process of precipitation with ammonium sulfate. Three fractions of ammonium sulfate were prepared: $0 \%-40 \%, 40 \%-60 \%$ and $60 \%-90 \%$ of saturation. After each saturation step the solution remained at $4{ }^{\circ} \mathrm{C}$ for approximately $20 \mathrm{~h}$ and then was centrifuged at $12,000 \times g$, for $30 \mathrm{~min}$, at $4{ }^{\circ} \mathrm{C}$. The precipitate resulted from each step were resuspended in sodium tetraborate $50 \mathrm{mM}$ buffer $(\mathrm{pH} 7.5)$ and subjected to dialysis at the same buffer.

The $40 \%-60 \%$ fraction, which showed the highest inhibitory activity against trypsin, was applied to a size exclusion chromatography SephacrylS-100 high resolution $(1.50 \times 115 \mathrm{~cm})$ equilibrated with Sodium tetraborate $50 \mathrm{mM}$ buffer, $\mathrm{pH} 7.5$, at flow of $1 \mathrm{~mL} \cdot \mathrm{min}^{-1}$. Fractions that showed inhibitory activity against trypsin were pooled and applied on to affinity column trypsin-Sepharose $(2.5 \times 2.0 \mathrm{~cm})$ previously equilibrated with sodium tetraborate $50 \mathrm{mM}$ buffer, $\mathrm{pH}$ 7.5. The proteins retained in the resin were eluted using $100 \mathrm{mM} \mathrm{HCl}$ solution at a flow of $40 \mathrm{~mL} \cdot \mathrm{h}^{-1}$. The absorbance was monitored at $280 \mathrm{~nm}$. The fractions with inhibitory activity against trypsin were dialyzed in distillated water, lyophilized, and named ApKTI. All fractions had the protein content measured by Bradford [50] using bovine serum albumin (BSA) as standard.

\subsection{Chromatography in Chitin Column}

A chitin column $(2.0 \times 2.5 \mathrm{~cm})$ was prepared and washed with $\mathrm{HCl} 10 \mathrm{mM}$, subsequently equilibrated with sodium tetraborate $50 \mathrm{mM}$ buffer, $\mathrm{pH}$ 7.5. ApKTI was applied to column and the elution carried out with $\mathrm{HCl} 100 \mathrm{mM}$. Fractions of $2 \mathrm{~mL}$ were collected, and the absorbance was monitored at $280 \mathrm{~nm}$.

\subsection{Kinetic Studies Between ApKTI and P. Interpunctella Trypsin}

Kinetic studies were carried out in order to investigate the mechanism of inhibition of ApKTI on trypsin from P. interpunctella. Three different concentrations of BApNA $(0.31 ; 0.62 ;$ and $1.25 \mathrm{mM})$ and increasing concentrations of ApKTI $(0.25 ; 0.5 ; 1 ; 3 ; 6 ; 9$; and $12 \mu \mathrm{g})$ were incubated with a fixed concentration of $P$. interpunctella gut extract. Followed the establishment of kinetic parameters $V_{\max }$ and $\mathrm{Km}$, the $\mathrm{Ki}$ (dissociation constant) values were determined.

\subsection{In Vitro Evaluation of Inhibitory Activity}

\subsubsection{Inhibitory Activity for Bovine Trypsin}

Assays to determine the inhibitory activity of trypsin were conducted using BApNA as substrate [51]. Ten microliters of trypsin solution $\left(0.3 \mathrm{mg} \cdot \mathrm{mL}^{-1}\right.$ prepared in $\left.2.5 \mathrm{mM} \mathrm{HCl}\right)$ was incubated for $10 \mathrm{~min}$ at $30^{\circ} \mathrm{C}$ with $100 \mu \mathrm{L}$ of ApKTI, $120 \mu \mathrm{L}$ of $2.5 \mathrm{mM} \mathrm{HCl}$ and $270 \mu \mathrm{L}$ of $50 \mathrm{mM}$ Tris- $\mathrm{HCl}$ buffer, $\mathrm{pH}$ 7.5. Followed the addition of $500 \mu \mathrm{L}$ of $1.25 \mathrm{mM}$ BApNA solution, prepared in $1 \%$ $(v / v)$ DMSO and $0.05 \mathrm{M}$ Tris- $\mathrm{HCl}, \mathrm{pH} 7.5$. The reaction occurred during $15 \mathrm{~min}$ at $30{ }^{\circ} \mathrm{C}$, being stopped by the addition of $150 \mu \mathrm{L}$ of $30 \%$ acetic acid solution. The formation of p-nitroaniline was measured by absorbance at $410 \mathrm{~nm}$. All assays were made in triplicate. 


\subsubsection{Insect Gut Peptidases}

A total of 50 P. interpunctella fifth-instar larvae were cold-immobilized on ice and had the gut surgically removed into an iso-osmotic saline $(150 \mathrm{mM} \mathrm{NaCl})$ solution. After homogenization, the gut tissue was centrifuged at $10,000 \times g$, at $4{ }^{\circ} \mathrm{C}$, for $10 \mathrm{~min}$. The supernatants were then recovered, had the protein content determined and were used as source of peptidases.

The activity of trypsin was determined using BApNA. Briefly, $20 \mu \mathrm{g}$ of gut extract were incubated for $10 \mathrm{~min}$ at $30^{\circ} \mathrm{C}$ Tris- $\mathrm{HCl} 50 \mathrm{mM}$ buffer, $\mathrm{pH}$ 9.5. Further, it was added $500 \mu \mathrm{L}$ of $1.25 \mathrm{mM}$ BApNA solution, prepared in $1 \%(v / v)$ DMSO and Tris- $\mathrm{HCl} 50 \mathrm{mM}$ buffer. The reaction occurred during $15 \mathrm{~min}$ at $30{ }^{\circ} \mathrm{C}$, being stopped by the addition of $150 \mu \mathrm{L}$ of $30 \%$ acetic acid solution. The formation of p-nitroaniline was measured by absorbance at $410 \mathrm{~nm}$. All assays were made in triplicate.

\subsection{Molecular Modeling}

Tridimensional theoretical models for ApKTI and trypsin/chymotrypsin from P. interpunctella were built using Modeller v. 9.12 [52]. ApKTI primary sequence was obtained from the National Center for Biotechnology Information (NCBI) under the accession numbers gi: 124152 and gi: 124153 [14] for the $\alpha$ and $\beta$ chains, respectively. P. interpunctella trypsin and chymotrypsin primary sequences were obtained from NCBI under the accession numbers gi: 3153854 [53] and gi: 2353158 [54], respectively. Trypsin and chymotrypsin signal peptides and transmembrane regions were predicted by Phobius server [55] and discarded from the simulations. ApKTI was modeled based on the crystallographic structure of a soybean trypsin inhibitor (PDB code: 1avw) [47], whereas P. interpunctella trypsin/chymotrypsin were modeled based on the crystallographic structure of a fire ant (Solenopsis invicta) chymotrypsin (PDB code: 1eq9) [56]. One hundred tridimensional theoretical models were generated and ranked according to their DOPE score. The lowest free-energy models were selected and validated by PROCHECK (stereochemical quality) [21] and ProSA-web (fold quality) [20] servers.

\subsection{Molecular Docking}

Molecular docking studies were carried out to predict the atomic interactions involved in the stabilization of the ApKTI/trypsin, ApKTI/chymotrypsin and ApKTI/N-acetylglucosamine (NAG) complexes. NAG coordinates were extracted from a hevein domain with binding affinity for chitooligosaccharides (PDB code: 1t0w) [57]. Grid boxes of $88 \times 88 \times 88$ (ApKTI/trypsin and ApKTI/chymotrypsin) and $44 \times 45 \times 51$ (ApKTI/NAG) points with $1 \AA$ spacing were built on AutoDock Tools [58]. Fifty runs of molecular docking simulations were performed using AutoDock Vina [58],

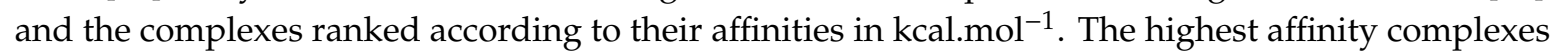
were submitted to energy minimization steps using the GROMOS $9646 \mathrm{~b} 1$ force field from SPDB Viewer v. 4.1.1 [59]. Further, all atomic interactions respecting the maximum distance of $3.6 \AA$ between all atoms (blind docking) were measured using PyMOL (http://pymol.sourceforce.net/).

\section{Conclusions}

Herein, we showed the insecticide effects of ApKTI on P. interpunctella larvae, demonstrating the potential this inhibitor for pest control. Based on a non-competitive inhibition mode, ApKTI was capable of compromising the larval digestive process, inhibiting trypsin and chymotrypsin enzymes. The ability of ApKTI to bind to chitin might affect the PM homeostasis, committing a variety of processes, including enzyme anchorage, compartmentalization of the gut lumen, and enzyme recycling. Together, these factors promote a limited absorption of nutrients that led ApKTI-fed larvae to death by starvation.

Supplementary Materials: The following are available online. Table S1: In silico interactions between ApKTI/N-acetylglucosamine; ApKTI/trypsin and ApKTI/chymotrypsin.

Author Contributions: Conceptualization, A.F.J.d.F. and C.F.R.d.O.; methodology, R.R. and A.S.d.O.; software, M.H.C. and K.G.N.O.; validation, M.H.C. and K.G.N.O.; formal analysis, A.S.d.O., T.M.d.O.F. and O.L.F.; 
writing—original draft preparation, A.F.J.d.F., C.F.R.d.O. and T.M.d.O.F.; writing—review and editing, E.A.d.S., O.L.F. and L.M.

Funding: This research was funded by CNPq, grant number (L.M. 307284/2018-2) and Postgraduate Program in Biochemistry from Federal University of Rio Grande do Norte.

Acknowledgments: This work was supported by the Brazilian funding agencies CNPq, CAPES and FUNDECT.

Conflicts of Interest: The authors declare that there are no conflict of interest.

\section{References}

1. Santamaria, M.E.; Cambra, I.; Martinez, M.; Pozancos, C.; González-Melendi, P.; Grbic, V.; Castañera, P.; Ortego, F.; Diaz, I. Gene pyramiding of peptidase inhibitors enhances plant resistance to the spider mite Tetranychus urticae. PLoS ONE 2012, 7, e43011. [CrossRef] [PubMed]

2. Le Goff, G.; Giraudo, M. Effects of Pesticides on the Environment and Insecticide Resistance. In Olfactory Concepts of Insect Control-Alternative to insecticides; Springer: Heidelberg, Germany, 2019; pp. 51-78.

3. Cui, J.; Luo, J.; Van Der Werf, W.; Ma, Y.; Xia, J. Effect of pyramiding Bt and CpTI genes on resistance of cotton to Helicoverpa armigera (Lepidoptera: Noctuidae) under laboratory and field conditions. J. Econ. Entomol. 2011, 104, 673-684. [CrossRef] [PubMed]

4. Senthilkumar, R.; Cheng, C.P.; Yeh, K.W. Genetically pyramiding protease-inhibitor genes for dual broad-spectrum resistance against insect and phytopathogens in transgenic tobacco. Plant Biotechnol. J. 2010, 8, 65-75. [CrossRef] [PubMed]

5. Amorim, T.M.; Macedo, L.L.; Uchoa, A.F.; Oliveira, A.S.; Pitanga, J.C.; Macedo, F.P.; Santos, E.A.; de Sales, M.P. Proteolytic digestive enzymes and peritrophic membranes during the development of Plodia interpunctella (Lepidoptera: Piralidae): Targets for the action of soybean trypsin inhibitor (SBTI) and chitin-binding vicilin (EvV). J. Agric. Food Chem. 2008, 56, 7738-7745. [CrossRef]

6. Lopes, A.R.; Sato, P.M.; Terra, W.R. Insect chymotrypsins: Chloromethyl ketone inactivation and substrate specificity relative to possible coevolutional adaptation of insects and plants. Arch. Insect Biochem. Physiol. 2009, 70, 188-203. [CrossRef]

7. Terra, W.R.; Ferreira, C. Insect digestive enzymes: Properties, compartmentalization and function. Comp. Biochem. Physiol. B Comp. Biochem. 1994, 109, 1-62. [CrossRef]

8. Gatehouse, J.A. Plant resistance towards insect herbivores: A dynamic interaction. New Phytologist 2002, 156, 145-169. [CrossRef]

9. Macedo, M.L.R.; Sá, C.M.; Freire, M.G.M.; Parra, J.R.P. A Kunitz-type inhibitor of coleopteran proteases, isolated from Adenanthera pavonina L. seeds and its effect on Callosobruchus maculatus. J. Agric. Food Chem. 2004, 52, 2533-2540. [CrossRef]

10. Boulter, D.; Gatehouse, A.; Hilder, V. Use of cowpea trypsin inhibitor (CpTI) to protect plants against insect predation. Biotechnol. Adv. 1989, 7, 489-497. [CrossRef]

11. Dunse, K.; Stevens, J.; Lay, F.; Gaspar, Y.; Heath, R.; Anderson, M. Coexpression of potato type I and II proteinase inhibitors gives cotton plants protection against insect damage in the field. Proc. Natl. Acad. Sci. USA 2010, 107, 15011-15015. [CrossRef]

12. Stevens, J.; Dunse, K.; Guarino, R.; Barbeta, B.; Evans, S.; West, J.; Anderson, M. The impact of ingested potato type II inhibitors on the production of the major serine proteases in the gut of Helicoverpa armigera. Insect Biochem. Mol. Biol. 2013, 43, 197-208. [CrossRef] [PubMed]

13. Macedo, M.L.R.; Mello, G.C.; Freire, M.G.M.; Novello, J.C.; Marangoni, S.; de Matos, D.G. Effect of a trypsin inhibitor from Dimorphandra mollis seeds on the development of Callosobruchus maculatus. Plant Physiol. Biochem. 2002, 40, 891-898. [CrossRef]

14. Richardson, M.; Campos, F.; Xavier-Filho, J.; Macedo, M.; Maia, G.; Yarwood, A. The amino acid sequence and reactive (inhibitory) site of the major trypsin isoinhibitor (DE5) isolated from seeds of the Brazilian Carolina tree (Adenanthera pavonina L.). Biochim. Biophys. Acta Protein Struc. Mol. Enzymol. 1986, 872, 134-140. [CrossRef]

15. Migliolo, L.; de Oliveira, A.S.; Santos, E.A.; Franco, O.L.; Maurício, P. Structural and mechanistic insights into a novel non-competitive Kunitz trypsin inhibitor from Adenanthera pavonina L. seeds with double activity toward serine-and cysteine-proteinases. J. Mol. Grap. Model. 2010, 29, 148-156. [CrossRef] 
16. Macedo, M.L.R.; Durigan, R.A.; da Silva, D.S.; Marangoni, S.; Freire, M.d.G.M.; Parra, J.R.P. Adenanthera pavonina trypsin inhibitor retard growth of Anagasta kuehniella (Lepidoptera: Pyralidae). Arch. Insect Biochem. Physiol. 2010, 73, 213-231.

17. da Silva, W.; Freire, M.d.G.M.; Parra, J.R.P.; Marangoni, S.; Macedo, M.L.R. Evaluation of the Adenanthera pavonina seed proteinase inhibitor (ApTI) as a bioinsecticidal tool with potential for the control of Diatraea saccharalis. Process Biochem. 2012, 47, 257-263. [CrossRef]

18. Sasaki, D.Y.; Jacobowski, A.C.; de Souza, A.P.; Cardoso, M.H.; Franco, O.L.; Macedo, M.L.R. Effects of proteinase inhibitor from Adenanthera pavonina seeds on short-and long term larval development of Aedes aegypti. Biochimie 2015, 112, 172-186. [CrossRef]

19. Prabhu, K.S.; Pattabiraman, T.N. Natural plant enzyme inhibitors. Isolation and characterisation of a trypsin/chymotrypsin inhibitor from indian red wood (Adenanthera pavonia) seeds. J. Sci. Food Agric. 1980, 31, 967-980. [CrossRef]

20. Wiederstein, M.; Sippl, M.J. ProSA-web: Interactive web service for the recognition of errors in three-dimensional structures of proteins. Nucleic Acids Res. 2007, 35, W407-W410. [CrossRef]

21. Laskowski, R.A.; Rullmann, J.A.C.; MacArthur, M.W.; Kaptein, R.; Thornton, J.M. AQUA and PROCHECK-NMR: Programs for checking the quality of protein structures solved by NMR. J. Biomol. NMR 1996, 8, 477-486. [CrossRef]

22. Chen, V.B.; Arendall, W.B.; Headd, J.J.; Keedy, D.A.; Immormino, R.M.; Kapral, G.J.; Murray, L.W.; Richardson, J.S.; Richardson, D.C. MolProbity: All-atom structure validation for macromolecular crystallography. Acta Cryst. D 2010, 66, 12-21. [CrossRef]

23. Boaventura, D.; Bolzan, A.; Padovez, F.E.; Okuma, D.M.; Omoto, C.; Nauen, R. Detection of a ryanodine receptor target-site mutation in diamide insecticide resistant fall armyworm, Spodoptera frugiperda. Pest Manag. Sci. 2019. [CrossRef] [PubMed]

24. Tabashnik, B.E.; Gassmann, A.J.; Crowder, D.W.; Carrière, Y. Insect resistance to Bt crops: Evidence versus theory. Nat. Biotechnol. 2008, 26, 199. [CrossRef] [PubMed]

25. Hilder, V.A.; Gatehouse, A.M.; Boulter, D. Transgenic plants conferring insect tolerance: Protease inhibitor approach. In Transgenic plants. Engineering and Utilization; Academic Press: San Diego, CA, USA, 1993; pp. 317-338.

26. Hilder, V.; Powell, K.; Gatehouse, A.; Gatehouse, J.; Gatehouse, L.; Shi, Y.; Hamilton, W.; Merryweather, A.; Newell, C.; Timans, J. Expression of snowdrop lectin in transgenic tobacco plants results in added protection against aphids. Transgenic Res. 1995, 4, 18-25. [CrossRef]

27. Jongsma, M.A.; Beekwilder, J. Co-evolution of insect proteases and plant protease inhibitors. Curr. Protein Pep. Sci. 2011, 12, 437-447. [CrossRef]

28. Habib, H.; Fazili, K.M. Plant protease inhibitors: A defense strategy in plants. Biotechnol. Mol. Biol. Rev. 2007, 2, 68-85.

29. Oliva, M.L.V.; Silva, M.C.; Sallai, R.C.; Brito, M.V.; Sampaio, M.U. A novel subclassification for Kunitz proteinase inhibitors from leguminous seeds. Biochimie 2010, 92, 1667-1673. [CrossRef]

30. Macedo, M.L.; de Oliveira, C.F.; Costa, P.M.; Castelhano, E.C.; Silva-Filho, M.C. Adaptive mechanisms of insect pests against plant protease inhibitors and future prospects related to crop protection: A review. Protein Pep. Lett. 2015, 22, 149-163. [CrossRef]

31. Kuwar, S.S.; Pauchet, Y.; Vogel, H.; Heckel, D.G. Adaptive regulation of digestive serine proteases in the larval midgut of Helicoverpa armigera in response to a plant protease inhibitor. Insect Biochem. Mol. Biol. 2015, 59, 18-29. [CrossRef]

32. Oliveira, C.F.R.; de Paula Souza, T.; Parra, J.R.P.; Marangoni, S.; de Castro Silva-Filho, M.; Macedo, M.L.R. Insensitive trypsins are differentially transcribed during Spodoptera frugiperda adaptation against plant protease inhibitors. Comp. Biochem. Physiol. B Biochem. Mol. Biol. 2013, 165, 19-25. [CrossRef]

33. Bown, D.P.; Wilkinson, H.S.; Gatehouse, J.A. Regulation of expression of genes encoding digestive proteases in the gut of a polyphagous lepidopteran larva in response to dietary protease inhibitors. Physiol. Entomol. 2004, 29, 278-290. [CrossRef]

34. Sales, M.P.; Pimenta, P.P.; Paes, N.S.; Grossi-de-Sá, M.F.; Xavier-Filho, J. Vicilins (7S storage globulins) of cowpea (Vigna unguiculata) seeds bind to chitinous structures of the midgut of Callosobruchus maculatus (Coleoptera: Bruchidae) larvae. Braz. J. Med. Biol. Res. 2001, 34, 27-34. [CrossRef] [PubMed] 
35. Kim, J.-Y.; Park, S.-C.; Hwang, I.; Cheong, H.; Nah, J.-W.; Hahm, K.-S.; Park, Y. Protease inhibitors from plants with antimicrobial activity. Int. J. Mol. Sci. 2009, 10, 2860-2872. [CrossRef] [PubMed]

36. Bhattacharyya, A.; Babu, C.R. Purification and biochemical characterization of a serine proteinase inhibitor from Derris trifoliata Lour. seeds: Insight into structural and antimalarial features. Phytochemistry 2009, 70, 703-712. [CrossRef]

37. Freire, M.G.M.; Franco, O.L.; Kubo, C.E.G.; Migliolo, L.; Vargas, R.H.; de Oliveira, C.F.R.; Parra, J.R.P.; Macedo, M.L.R. Structural insights regarding an insecticidal Talisia esculenta protein and its biotechnological potential for Diatraea saccharalis larval control. Comp. Biochem. Physiol. B Biochem. Mol. Biol. 2012, 161, 86-92. [CrossRef]

38. Oliveira, C.F.R.; Marangoni, S.; Macedo, M.L.R. The trypsin inhibitor from Entada acaciifolia seeds affects negatively the development of Mediterranean flour moth, Anagasta kuehniella. Pestic. Biochem. Physiol. 2014, 108, 74-79. [CrossRef]

39. Sumikawa, J.T.; Brito, M.V.d.; Macedo, M.L.R.; Uchoa, A.F.; Miranda, A.; Araujo, A.P.U.; Silva-Lucca, R.A.; Sampaio, M.U.; Oliva, M.L.V. The defensive functions of plant inhibitors are not restricted to insect enzyme inhibition. Phytochemistry 2010, 71, 214-220. [CrossRef]

40. Bhattacharyya, A.; Leighton, S.M.; Babu, C. Bioinsecticidal activity of Archidendron ellipticum trypsin inhibitor on growth and serine digestive enzymes during larval development of Spodoptera litura. Comp. Biochem. Physiol. C Toxicol. Pharmacol. 2007, 145, 669-677. [CrossRef]

41. Zhu-Salzman, K.; Zeng, R. Insect response to plant defensive protease inhibitors. Annu. Rev. Entomol. 2015, 60, 233-252. [CrossRef]

42. Souza, T.P.; Dias, R.O.; Castelhano, E.C.; Brandao, M.M.; Moura, D.S.; Silva-Filho, M.C. Comparative analysis of expression profiling of the trypsin and chymotrypsin genes from Lepidoptera species with different levels of sensitivity to soybean peptidase inhibitors. Comp. Biochem. Physiol. B Biochem. Mol. Biol. 2016, 196, 67-73. [CrossRef]

43. Dias, R.O.; Via, A.; Brandão, M.M.; Tramontano, A.; Silva-Filho, M.C. Digestive peptidase evolution in holometabolous insects led to a divergent group of enzymes in Lepidoptera. Insect Biochem. Mol. Biol. 2015, 58, 1-11. [CrossRef] [PubMed]

44. Lopes, A.; Juliano, M.; Marana, S.; Juliano, L.; Terra, W. Substrate specificity of insect trypsins and the role of their subsites in catalysis. Insect Biochem. Mol. Biol. 2006, 36, 130-140. [CrossRef] [PubMed]

45. Lopes, A.R.; Juliano, M.A.; Juliano, L.; Terra, W.R. Coevolution of insect trypsins and inhibitors. Arch. Insect Biochem. Physiol. 2004, 55, 140-152. [CrossRef] [PubMed]

46. Sweet, R.; Wright, H.; Janin, J.; Chothia, C.; Blow, D. Crystal structure of the complex of porcine trypsin with soybean trypsin inhibitor (Kunitz) at $2.6 \AA$ resolution. Biochemistry 1974, 13, 4212-4228. [CrossRef] [PubMed]

47. Song, H.K.; Suh, S.W. Kunitz-type soybean trypsin inhibitor revisited: Refined structure of its complex with porcine trypsin reveals an insight into the interaction between a homologous inhibitor from Erythrina caffra and tissue-type plasminogen activator. J. Mol. Biol. 1998, 275, 347-363. [CrossRef] [PubMed]

48. Macedo, M.L.R.; Freire, M.G.M.; Franco, O.L.; Migliolo, L.; Oliveira, C.F.R. Practical and theoretical characterization of Inga laurina Kunitz inhibitor on the control of Homalinotus coriaceus. Comp. Biochem. Physiol. B Biochem. Mol. Biol. 2011, 158, 164-172. [CrossRef] [PubMed]

49. Sattar, R.; Ali, S.A.; Kamal, M.; Khan, A.A.; Abbasi, A. Molecular mechanism of enzyme inhibition: Prediction of the three-dimensional structure of the dimeric trypsin inhibitor from Leucaena leucocephala by homology modelling. Biochem. Biophys. Res. Commun. 2004, 314, 755-765. [CrossRef]

50. Bradford, M.M. A rapid and sensitive method for the quantitation of microgram quantities of protein utilizing the principle of protein-dye binding. Anal. Biochem. 1976, 72, 248-254. [CrossRef]

51. Erlanger, B.F.; Kokowsky, N.; Cohen, W. The preparation and properties of two new chromogenic substrates of trypsin. Arch. Biochem. Biophys. 1961, 95, 271-278. [CrossRef]

52. Eswar, N.; Webb, B.; Marti-Renom, M.A.; Madhusudhan, M.; Eramian, D.; Shen, M.y.; Pieper, U.; Sali, A. Comparative protein structure modeling using Modeller. Curr. Protoc. Bioinformatics 2006, 15, 5.6.1-5.6.30. [CrossRef]

53. Zhu, Y.; Oppert, B.; Kramer, K.; McGaughey, W.; Dowdy, A. cDNA sequence, mRNA expression and genomic DNA of trypsinogen from the indianmeal moth, Plodia interpunctella. Insect Mol. Biol. 2000, 9, 19-26. [CrossRef] [PubMed] 
54. Zhu, Y.-C.; Oppert, B.; Kramer, K.J.; McGaughey, W.H.; Dowdy, A.K. cDNAs for a chymotrypsinogen-like protein from two strains of Plodia interpunctella. Insect Biochem. Mol. Biol. 1997, 27, 1027-1037. [CrossRef]

55. Käll, L.; Krogh, A.; Sonnhammer, E.L. Advantages of combined transmembrane topology and signal peptide prediction—the Phobius web server. Nucleic Acids Res. 2007, 35, W429-W432. [CrossRef] [PubMed]

56. Botos, I.; Meyer, E.; Nguyen, M.; Swanson, S.M.; Koomen, J.M.; Russell, D.H.; Meyer, E.F. The structure of an insect chymotrypsin. J. Mol. Biol. 2000, 298, 895-901. [CrossRef] [PubMed]

57. Aboitiz, N.; Vila-Perelló, M.; Groves, P.; Asensio, J.L.; Andreu, D.; Cañada, F.J.; Jiménez-Barbero, J. NMR and modeling studies of protein-carbohydrate interactions: Synthesis, three-dimensional structure, and recognition properties of a minimum hevein domain with binding affinity for chitooligosaccharides. ChemBioChem 2004, 5, 1245-1255. [CrossRef]

58. Trott, O.; Olson, A.J. AutoDock Vina: Improving the speed and accuracy of docking with a new scoring function, efficient optimization, and multithreading. J. Comput. Chem. 2010, 31, 455-461. [CrossRef]

59. Guex, N.; Peitsch, M.C. SWISS-MODEL and the Swiss-Pdb Viewer: An environment for comparative protein modeling. Electrophoresis 1997, 18, 2714-2723. [CrossRef]

Sample Availability: Samples of the compounds are not available from the authors.

(C) 2019 by the authors. Licensee MDPI, Basel, Switzerland. This article is an open access article distributed under the terms and conditions of the Creative Commons Attribution (CC BY) license (http://creativecommons.org/licenses/by/4.0/). 